\title{
Evaluating the Chichewa version of the London Measure of Unplanned Pregnancy in Malawi: a validation update
}

\author{
Jennifer A. Hall ${ }^{*} \mathbb{D}$, Judith Stephenson and Geraldine Barrett
}

\begin{abstract}
Objective: To investigate the psychometric properties of the validated Chichewa version of the London Measure of Unplanned Pregnancy in a large representative community-based sample in Malawi, a low-income country. We collected data on pregnancy intention from a cohort of 4244 pregnant women in Malawi using the validated Chichewa version of the London Measure of Unplanned Pregnancy (LMUP). We evaluated the psychometric properties of the Chichewa LMUP using classical test theory and confirmatory factor analysis to re-assess the performance of items one and six, which had weaker performance in the original smaller, facility-based validation sample.

Results: The Chichewa version of the LMUP met all pre-set criteria for validation. There are now nine validations of the LMUP in different low-and-middle-income countries, confirming the validity and applicability of the LMUP in these settings.
\end{abstract}

Keywords: Pregnancy intention, Measurement, London Measure of Unplanned Pregnancy, Malawi, Psychometric, Validation, Chichewa

\section{Introduction}

The London Measure of Unplanned Pregnancy (LMUP) is a psychometrically validated measure of pregnancy intention that was developed in the United Kingdom in the early 2000s $[1,2]$. Using six questions, scored zero, one or two, it produces a score of zero-to-12, with higher scores indicating a more planned/intended pregnancy. Since its publication it has been translated and validated in diverse settings and populations around the world. As of May 2021 there are seventeen validated language versions across 14 countries, including nine low- and middle-income countries [2-15], with more in progress.

The original evaluation of the Chichewa LMUP in Malawi in 2013 found the measure to be acceptable to women and psychometrically valid [4]. The Cronbach's

\section{*Correspondence: jennifer.hall@ucl.ac.uk}

Research Department of Reproductive Health, UCL Institute for Women's Health, London, UK $\alpha$ (a measure of internal consistency) was 0.78 (above the standard cut point of 0.7 [16]). Item-rest correlations (which should be $>0.2$ [17]) were at least 0.7 for four of the six questions, was borderline for the preconception preparation question (0.16) and was low for the contraception question (0.05). Hypothesis testing confirmed construct validity and principal component analysis confirmed unidimensionality (the Eigenvalue of the first component was 3.1), albeit with a borderline second compenent (Eigenvalue 1.0) which mostly represented the contraception question (loading 0.99). A sensitivity analysis to assess the effect of the removal of the contraceptive item (item one) showed slightly improved performance of the measure but as the LMUP was not significantly adversely affected by its inclusion, and for the purposes of international comparability, tracking of trends, and future relevance, we recommended retaining it. 
The LMUP includes two behavioural items: question one on contraception and question six on preconceptual preparations. There are lower levels of both contraceptive use and preconceptual preparations in Malawi, and also more generally in sub-Saharan African countries, compared with the United Kingdom and other developed countries. Despite this, the pattern of the relationship of the items of the LMUP has been remarkably stable across international contexts: items two-to-five most strongly correlated with the overall score; items one and six (the behaviour items) less strongly correlated; and all items positively correlated with each other. Given the importance of improving pregnancy intention measurement in low-and-middle-income countries, and in particular the call to provide evidence on the performance of the LMUP in such [18], we sought to re-examine the performance of the Chichewa LMUP using data from a large, representative community-based cohort study of pregnant women in Mchini District, Malawi [19]. We were particularly interested to review the performance of items one and six given their poorer performance in the original validation, which was conducted on a smaller, facility-based sample of 125 women.

\section{Main text \\ Methodology}

4244 pregnant women in Mchinji District, Malawi, completed the Chichewa LMUP between March 2013 and July 2014. Pregnant women were identified by a community-based surveillance system and were visited, consented and interviewed at home by one of 25 local data collectors. A full description of the recruitment and of the cohort has previously been published [19]. Mchinji District is a rural area, where most inhabitants are subsistence farmers with very low levels of education.

We evaluated the LMUP using Classical Test Theory, in keeping with its development [2] and the previous Chichewa validation [4]. Rates of missing data for each item were assessed, as high levels of missing data can indicate a problem with the understanding of acceptability of an item [20]. Item discrimination was assessed by examining the endorsement of item response options. Internal consistency was assessed using the Cronbach's $\alpha$ with a cut-point of 0.7 [16] and examination of each question's item-rest correlation, accepting a minimum correlation of 0.20 [17]. Inter-item correlations were assessed to check they were all positive. To assess structural (construct) validity, we conducted a principal component analysis (PCA) looking for one component with an Eigenvalue larger than one to demonstrate that all items are measuring the same construct [21]. In keeping with recent recommended standards of assessment [22], confirmatory factor analysis (CFA) was carried out to assess model fit (in this case the six items to a unidimensional model). Model fit was assessed by the comparative fit index (CFI), with $>0.95$ indicating acceptable model fit, and standardised root mean squared residual (SRMR), with $<0.08$ indicating acceptable model fit. We also conducted a Mokken analysis, as other validations of the LMUP have, to confirm that the items vary in 'difficulty' and that women answered the LMUP questions in keeping with how planned their pregnancy was. A Loevinger $\mathrm{H}$ coefficient of $>0.5$ indicates a 'strong' scale [23].

All analyses were conducted in STATA version 15 (StataCorp. 2017. Stata Statistical Software: Release 15. College Station, TX: StataCorp LLC).

\section{Results}

Missing data were very rare, with only 19 missing answers out of 25464 questions asked (the six LMUP questions asked of 4244 women), as shown in Table 1, suggesting extremely good acceptability. No question response had more than $80 \%$ endorsement. For questions one to five the more planned option was the most frequently endorsed, whereas for question six, preconception preparations, a lack of preparation was most common.

The full range of LMUP scores from zero to twelve was captured. The median score was nine, inter-quartile range three-to- 11 . The Chronbach's alpha was 0.89 and, as shown in Table 2, all item-rest correlations were above 0.2. Principal components analysis confirmed that all items loaded on to one component with an Eigenvalue of 3.95. The Mokken analysis showed the LMUP was a 'strong' scale, with an overall Loevinger $\mathrm{H}$ coefficient of 0.733. The CFA confirmed a single factor model (CFI 0.997, SRMR 0.015).

\section{Discussion}

In this large representative community dataset, from a rural area in Malawi, a low-income country, the psychometric properties of the Chichewa LMUP met all prespecified criteria and international standards. In particular, the item-rest correlations for questions one and six, i.e. the behavioural components of contraceptive use and preconception preparations, were higher than in the initial validation and were both above the cut-point of 0.2 [4]. The pre-to-post birth stability of the Chichewa LMUP has previously been investigated in this sample [24]. This showed that the LMUP has moderate to substantial stability between pregnancy and up to 12 months postpartum (AC 0.54-0.64).

Since these data were collected there has been one other assessment of the psychometric properties of the Chichewa LMUP in Malawi by Yeatman and Greenaway [25]. In their study of 645 women, the Chichewa LMUP also demonstrated excellent psychometric properties: 
Table 1 Participant's responses to each of the six London Measure of Unplanned Pregnancy questions

\begin{tabular}{|c|c|c|}
\hline Response to LMUP questions & Freq & Percent \\
\hline \multicolumn{3}{|l|}{ Q1-Contraception } \\
\hline Always used contraception & 230 & 5.42 \\
\hline Sometimes used contraception/knew the method failed & 1187 & 28.0 \\
\hline Not using contraception & 2823 & 66.5 \\
\hline Missing & 4 & 0.09 \\
\hline Total & 4244 & 100 \\
\hline \multicolumn{3}{|l|}{ Q2-Timing } \\
\hline Wrong time & 1460 & 34.6 \\
\hline Ok, but not quite right time & 431 & 10.2 \\
\hline Right time & 2344 & 55.2 \\
\hline Missing & 1 & 0.02 \\
\hline Total & 4244 & 100 \\
\hline \multicolumn{3}{|l|}{ Q3-Intention } \\
\hline Did not intend to get pregnant & 1628 & 38.4 \\
\hline Intentions kept changing & 310 & 7.30 \\
\hline Intended to get pregnant & 2304 & 54.2 \\
\hline Missing & 2 & 0.05 \\
\hline Total & 4243 & 100 \\
\hline \multicolumn{3}{|l|}{ Q4-Desire } \\
\hline Did not want to have a baby & 1438 & 33.9 \\
\hline Mixed feelings about having a baby & 462 & 10.9 \\
\hline Wanted to have a baby & 2344 & 55.2 \\
\hline Total & 4244 & 100 \\
\hline \multicolumn{3}{|l|}{ Q5_Partner discussions } \\
\hline Never discussed having children together & 970 & 22.9 \\
\hline Discussed having children, but had not agreed to get pregnant & 1011 & 23.8 \\
\hline Agreed we would like me to be pregnant & 2261 & 53.3 \\
\hline Missing & 2 & 0.05 \\
\hline Total & 4244 & 100 \\
\hline \multicolumn{3}{|l|}{ Q6-Preconception preparation } \\
\hline No action to prepare for pregnancy & 2710 & 63.9 \\
\hline 1 action to prepare for pregnancy & 1055 & 24.9 \\
\hline$\geq 2$ actions to prepare for pregnancy & 469 & 11.1 \\
\hline Missing & 10 & 0.24 \\
\hline Total & 4244 & 100 \\
\hline
\end{tabular}

Table 2 Results of classical test theory, principal component, Mokken and confirmatory factor analyses

\begin{tabular}{llllll}
\hline & N & $\begin{array}{l}\text { Item-rest correlation } \\
\text { coefficient }\end{array}$ & $\begin{array}{l}\text { PCA component 1 } \\
\text { loading }\end{array}$ & $\begin{array}{l}\text { Loevinger H } \\
\text { coefficient }\end{array}$ & $\begin{array}{l}\text { CFA factor } \\
\text { loadings }\end{array}$ \\
\hline Q1-Contraception & 4240 & 0.283 & 0.185 & 0.320 & 0.285 \\
Q2-Timing & 4243 & 0.878 & 0.469 & 0.791 & 0.930 \\
Q3-Intention & 4242 & 0.899 & 0.478 & 0.816 & 0.959 \\
Q4-Desire & 4244 & 0.891 & 0.473 & 0.799 & 0.942 \\
Q5-Partner discussions & 4242 & 0.809 & 0.446 & 0.770 & 0.846 \\
Q6-Preconception preparation & 4234 & 0.504 & 0.310 & 0.755 & 0.507 \\
\hline
\end{tabular}


Chronbach's alpha $=0.86$; all item-rest correlations $>0.2$, including the contraception and preconception questions; principal components analysis demonstrating one component/unidimensional measurement; and a full range of scores with a bimodal distribution.

Hence, there have now been three analyses of the Chichewa LMUP in independent samples in Malawi, with the two more recent and larger studies demonstrating good psychometric properties. In addition to this, there are now 12 validationated language versions in a further eight low-or-middle-income countries: Uganda [14]; Sierra Leone [13]; Sri Lanka [12]; Pakistan [9]; India [6]; Iran [7]; Turkey [15] and Brazil [3]. The authors are aware of ongoing evaluations in Nepal, Botswana, Mexico, Tanzania, Mozambique, South Africa, India and elsewhere. In 2015, the Population Council's Expert meeting on 'Conceptualizing and Measuring Unintended Pregnancy and Birth' recognised that the LMUP overcame many of the limitations of previous assessments of unplanned pregnancy but were concerned that, at that time, there was limited evidence of its validity outside high-income settings [18]. This concern is no longer founded. There is also growing evidence of the limitations of other methods, such as the Demographic and Health Survey questions which have recall bias and are affected by maternal characteristics and pregnancy outcomes, which the LMUP overcomes [24, 26-30].

\section{Conclusions}

This large community-based dataset confirms the validity of the LMUP in a rural, low-income country setting. Furthermore, the item-rest correlations, coefficient and factor loadings for the contraception and preconception preparation questions demonstrate that these items are relevant in this context in all the analyses conducted. Given this, and the accumulating validations of the LMUP in other low- and middle-income countries, there is now convincing evidence of the validity of the LMUP, and the relevance of questions on contraception and preconception preparation, in diverse settings around the world.

\section{Limitations}

The main limitation of this study is that, as women were recruited on average in the fifth month of pregnancy, we missed abortions and early miscarriages. Despite this, we captured the full range of pregnancies intentions (scores from zero to 12).

\section{Abbreviations}

CFA: Confirmatory factor analysis; CFI: Comparative fit index; LMUP: London Measure of Unplanned Pregnancy; PCA: Principal components analysis; SRMR: Standardised root mean squared residual.

\section{Acknowledgements}

We would like to thank the LMUP team fieldworkers who collected the data used in this analysis as well as all the women who consented to take part in the study from which these data were drawn.

\section{Authors' contributions}

Conceptualization JH, GB; Data curation JH; Formal Analysis JH, GB; Funding acquisition JH; Investigation JH; Methodology JH, GB, JS; Project administration JH; Supervision GB, JS; Validation JH, GB, JS; Writing - original draft JH, GB; Writing - review and editing JH, GB, JS. All authors read and approved the final manuscript.

\section{Funding}

The study from which these data were drawn was funded by a 3-year personal Research Training Fellowship from the Wellcome Trust to Dr. J Hall, Award number 097268/Z/11/Z. The funders had no role in the design, collection, analysis, or interpretation of data; in the writing of the manuscript; or in the decision to submit the manuscript for publication.

\section{Availability of data and materials}

The dataset supporting the conclusions of this article is available from the UCL Discovery database linked to the publication record in the UCL Research Publication Service. The dataset can be accessed here: http://www.homep ages.ucl.ac.uk/ uccaags/00/6.html (https://doi.org/10.5522/00/6). Data from the study are also available from the corresponding author who may be contacted at jennifer.hall@ucl.ac.uk.

The Chichewa LMUP is available at www.Imup.org.uk/docs/Chichewa_LMUP. docx

\section{Declarations}

\section{Ethics approval and consent to participate}

The study from which these data were drawn was approved by the UCL Research Ethics Committee and the College of Medicine Research Ethics Committee at the University of Malawi, reference numbers 3974/001 and P.03/12/1273 respectively. All participants gave written informed consent to take part in this research.

\section{Consent for publication}

Not applicable.

\section{Competing interests}

The authors declare that they have no competing interests.

Received: 3 December 2020 Accepted: 3 June 2021

Published online: 10 June 2021

\section{References}

1. Barrett G, Wellings K. What is a "planned" pregnancy? Empirical data from a British study. Soc Sci Med. 2002;55:545-57.

2. Barrett G, Smith SC, Wellings K. Conceptualisation, development and evaluation of a measure of unplanned pregnancy. J Epidemiol Community Health. 2004;58:426-33.

3. Borges AL, Barrett G, Dos Santos OA, Nascimento Nde C, Cavalhieri FB, Fujimori E. Evaluation of the psychometric properties of the London Measure of Unplanned Pregnancy in Brazilian Portuguese. BMC Pregnancy Childbirth. 2016;16:244.

4. Hall JA, Barrett G, Mbwana N, Copas A, Malata A, Stephenson J. Understanding pregnancy planning in a low-income country setting: validation of the London Measure of Unplanned Pregnancy in Malawi. BMC Pregnancy Childbirth. 2013;5(13):200.

5. Morof D, Steinauer JE, Haider S, Liu S, Darney P. Evaluation of the London Measure of Unplanned Pregnancy in a United States population of women. PLoS ONE. 2012;7(7):e35381.

6. Rocca CH, Krishnan S, Barrett G, Wilson M. Measuring pregnancy planning: an assessment of the London Measure of Unplanned Pregnancy among urban, south Indian women. Demogr Res. 2010;23:293-334. 
7. Roshanaei S, Shaghaghi A, Jafarabadi MA, Kousha A. Measuring unintended pregnancies in postpartum Iranian women: validation of the London Measure of Unplanned Pregnancy. East Mediterr Health J. 2015;21(8):572-8.

8. Almaghaslah E, Rochat R, Farhat G. Validation of a pregnancy planning measure for Arabic-speaking women. PLoS ONE. 2017;12(10):e0185433.

9. Habib MA, Raynes-Greenow C, Nausheen S, Soofi SB, Sajid M, Bhutta ZA et al. Prevalence and determinants of unintended pregnancies amongst women attending antenatal clinics in Pakistan. BMC Pregnancy Childbirth. 2017;17(1):156.

10. Goossens J, Verhaeghe S, Van Hecke A, Barrett G, Delbaere I, Beeckman D. Psychometric properties of the Dutch version of the London Measure of Unplanned Pregnancy in women with pregnancies ending in birth. PLoS ONE. 2018;13(4):e0194033.

11. Lang AY, Hall JA, Boyle JA, Harrison CL, Teede H, Moran L, et al. Validation of the London Measure of Unplanned Pregnancy among pregnant Australian women. PLoS ONE. 2019;14(8):e0220774.

12. Ranatunga I, Jayaratne K. Proportion of unplanned pregnancies, their determinants and health outcomes of women delivering at a teaching hospital in Sri Lanka. BMC Pregnancy Childbirth. 2020;20(1):667.

13. Brima N, Samba TT, Yamba A, Barrett G, Stephenson J, Hall J. Evaluation of the Krio Language Version of the London Measure of Unplanned Pregnancy in Western Area, Sierra Leone. Afr J Reprod Health. 2019:23(4):81-91.

14. Bukenya JN, Nalwadda CK, Neema S, Kyambadde P, Wanyenze RK, Barrett G. Pregnancy planning among female sex workers in Uganda: evaluation of the psychometric properties of the London Measure of Unplanned Pregnancy. Afr J Reprod Health. 2019;23(3):79-95.

15. Altiparmak S, Yilmaz AN, Aksoy DY. The Turkish validity and reliability study of the London measure of unplanned pregnancy. J Obstet Gynaecol Res. 2021;47(4):1362-70.

16. Cronbach LJ. Essentials of psychologic testing. 5th ed. New York: Harper \& Row; 1990.

17. Streiner D, Norman G. Health measurement scales: a practical guide to their development and use. Oxford: Oxford University Press; 2008.

18. Population Council. Conceptualizing and measuring unintended pregnancy and birth moving the field forward. Accra: Population Council; 2015.

19. Hall JA, Barrett G, Phiri T, Copas A, Malata A, Stephenson J. Prevalence and determinants of unintended pregnancy in Mchinji District,
Malawi; using a conceptual hierarchy to inform analysis. PLoS ONE. 2016;11(10):e0165621.

20. Loewenthal K. An introduction to psychological tests and scales. 2nd ed. London: Psychology Press; 2001.

21. Kline P. The new psychometrics: science, psychology and measurement London: Routledge; 1998

22. Prinsen CA, Vohra S, Rose MR, Boers M, Tugwell $P$, Clarke M, et al. How to select outcome measurement instruments for outcomes included in a "Core Outcome Set" — a practical guideline. Trials. 2016;17(1):449.

23. Mokken RJ. A theory and procedure of scale analysis. Berlin: De Gruyter; 1971.

24. Hall JA, Stephenson J, Barrett G. On the stability of reported pregnancy intentions from pregnancy to 1 year postnatally: impact of choice of measure, timing of assessment, women's characteristics and outcome of pregnancy. Matern Child Health J. 2019;23(9):1177-86.

25. Yeatman S, Smith-Greenaway E. Birth planning and women's and men's health in Malawi. Stud Fam Plann. 2018;49:213-35.

26. Hall JA, Stephenson J, Barrett G. What is the effect of question order on assessing pregnancy intention? Comparing the London Measure of Unplanned Pregnancy and the Demographic and Health Survey questions in Malawi. BMC Res Notes. 2018;11:487.

27. Smith-Greenaway E, Sennott C. Death and desirability: retrospective reporting of unintended pregnancy after a child's death. Demography. 2016:53(3):805-34.

28. Joyce T, Kaestner R, Korenman S. The stability of pregnancy intentions and pregnancy related maternal behaviors. Matern Child Health J. 2000;4(3):171-8.

29. Joyce T, Kaestner R, Korenman S. On the validity of retrospective assessments of pregnancy intention. Demography. 2002;39(1):199-213.

30. Koenig MA, Acharya R, Singh S, Roy TK. Do current measurement approaches underestimate levels of unwanted childbearing? Evidence from rural India. Popul Stud. 2006;60(3):243-56.

\section{Publisher's Note}

Springer Nature remains neutral with regard to jurisdictional claims in published maps and institutional affiliations.
Ready to submit your research? Choose BMC and benefit from:

- fast, convenient online submission

- thorough peer review by experienced researchers in your field

- rapid publication on acceptance

- support for research data, including large and complex data types

- gold Open Access which fosters wider collaboration and increased citations

- maximum visibility for your research: over $100 \mathrm{M}$ website views per year

At $\mathrm{BMC}$, research is always in progress.

Learn more biomedcentral.com/submissions 